\title{
Raios de democracia: prevenção e repressão do abuso de poder econômico
}

\author{
Fabiana Plican Ciena ${ }^{1}$
}

\begin{abstract}
Resumo
Os direitos políticos não se resumem à escolha do representante. Imprescindível a garantia do direito de consciência política objetivando a melhoria na organização da sociedade. Garantindo o direito de escolha do cidadão, a política oligarquizada, tendente a um afastamento de decisões importantes das instituições da representação popular, estará se transformando dia-a-dia para o ideal de democracia participativa. Para isso surge a necessidade de uma transformação interna da sociedade civil. Há constante abuso de poder econômico e corrupção no processo eleitoral, com sórdida concessão de cestas básicas, remédios e promessas de emprego a pessoas carentes de qualquer ação estatal, jogadas à sorte do poder econômico eleitoral. Desnecessária a ação de impugnação de mandato eletivo nas hipóteses do artigo 41-A da Lei $n$ o 9.405/97, bastando a investigação judicial eleitoral para reprimir a afronta ao direito de escolha do cidadão, garantia constitucional no conjunto dos direitos fundamentais. Cassando de imediato o registro ou o diploma, se já expedido, o artigo 41-A da Lei 9.504/94 pune tais atos, considerando a individualidade do eleitor no seu direito de livre escolha, com evidente tratamento diferenciado dos casos de abuso de poder que danificam a eleição como um todo e implicam em inelegibilidade. Não há mera potencialidade, mas sim, efetiva quebra da lisura do processo eleitoral, quando saúde, educação, moradia e emprego não são garantidos anteriormente a disputas eleitorais. Neste desequilíbrio estatal, urge a ação do Poder Judiciário forçando a implementação de políticas públicas para efetivo direito de escolha do cidadão. Apesar de renomados juristas defenderem a maior participação do cidadão no processo eleitoral, o Tribunal Superior Eleitoral a restringe à notícia fundamentada da inelegibilidade. Ciente de que o poder está concentrado muito mais nas mãos dos que deveriam legislar e destinar verbas para o combate à miséria, cada Magistrado, em sua jurisdição, deve exercer sua função de mostrar a justiça, sempre com sensibilidade. O povo jurisdicionado clama por justiça. O direito ao voto é apenas um dos raios deste imenso sol que se almeja: a democracia.
\end{abstract}

Palavras-Chave: Democracia; Direitos Fundamentais; Direito de Escolha; Ação de Impugnação de Mandato Eletivo; Investigação Judicial Eleitoral; Compra de voto; Abuso de Poder Econômico.

Especialista em Direito do Estado - Direito Constitucional pela Universidade Estadual de Londrina. 


\section{Introdução}

O abuso do poder econômico nas eleições é uma constante caricatura do Estado democrático, carente de uma educação para a cidadania. O cidadão consciente não vende seu voto, e se, apesar de consciente, o vende, deve ser punido. Há um constante jogo de interesses nos momentos que antecedem o voto, porém a verdadeira preocupação é saber até que ponto o poder de escolha do cidadão é garantido.

\section{0 direito de escolha do cidadão}

Direitos políticos são direitos públicos subjetivos que investem o indivíduo no poder de governo do país. Para Pimenta Bueno (1958, p. 459) os direitos políticos:

são o Jus Civitatis, os direitos cívicos, que se referem ao Poder Público, que autorizam o cidadão ativo a participar na formação ou exercício da autoridade nacional, a exercer o direito de votante ou eleitor, o direito de deputado ou senador, a ocupar cargos políticos e a manifestar suas opiniões sobre o governo do Estado.

Entende Alexandre de Moraes (2005, p. 208) que direitos políticos são: direito de sufrágio; alistabilidade (direito de votar em eleições, plebiscitos e referendos); elegibilidade; iniciativa popular de lei; ação popular; organização e participação de partidos políticos. Apesar da nobre concepção do jurista, os direitos políticos não se resumem à escolha do representante. Fundamentam-se principalmente no direito de consciência política objetivando a melhoria na organização da sociedade. Não se cogita aqui um Paraíso, mas o cidadão quer livrar-se (e livrar-nos) do Inferno.

Urgente se faz a implementação de uma educação cidadã. Para Francisco de Oliveira (2003, p. 52):

A política é largamente oligarquizada pelos partidos e os governos tornam-se mais e mais intransparentes; nas mais das vezes a institucionalidade erige-se em barreira à participação popular. Decisões cruciais que dizem respeito à macroeconomia e, embora não pareçam, à vida cotidiana dos cidadãos e eleitores, correm por fora das instituições da representação popular, até mesmo na sua instância máxima, que é o poder executivo. Tais tendências estão dizendo, à maneira de George Soros, que o voto popular é supérfluo, economicamente irrelevante e até um estorvo, que as instituições democráticas e republicanas são o pão - escasso - do circo - amplo - para manter as energias cidadãs entretidas enquanto os grupos econômicos decidem o que é relevante. A democracia e a 
república são o luxo que o capital têm que conceder às massas, dando-lhes a ilusão de que controlam os processos vitais, enquanto as questões reais são decididas em instâncias restritas, inacessíveis, e livres de qualquer controle.

Despertando a cidadania, além de se estar cumprindo os ditames do Estatuto da Criança e do Adolescente (assim como de todos os demais documentos internacionais pertinentes aos direitos fundamentais das crianças e adolescentes), certamente se estará dando qualidade futura ao direito de sufrágio exercido não somente pelo voto, mas também pela participação na organização do Estado. Respondendo o Poder Público concretamente ao seu dever institucional de assegurar a todas as crianças e adolescentes - com prioridade absoluta - o exercício dos direitos elementares da cidadania, indiscutivelmente caminhar-seá para contexto real inibidor da barbárie e, de conseqüência, determinante de efetiva democracia participativa.

Urge uma transformação interna, pessoal, conquistada por constante reivindicação da própria sociedade pela educação para a cidadania. Conforme anotações realizadas, Leonardo Prota destaca ${ }^{2}$ que a bioética deve fundamentar, prevenir, educar as crianças para tomar decisões. Se o objetivo do ensino fundamental é educar para a cidadania, a bioética deve tratar desse tema como prioritário. O ensino fundamental está em grau terminal. Deve ensinar tudo quanto é imprescindível para tornar o jovem em condição de cidadão, independente. Formação para a cidadania inclui vivência de valores (vida, trabalho, família). O educando deve decidir pelo bem. Não se pode impor o bem. Toda mudança social vem do interior de cada um.

Distante de qualquer absurdo de afastar a responsabilidade estatal, a cidadania está em cada movimento de reivindicação: segurança (tornando desnecessária qualquer arma); educação para a cidadania (saber o por quê do porque); vida digna (a fome ressalta os instintos primitivos); políticas econômicas que livrem o cidadão das mais variadas escravidões (juros excessivos são desastrosos); acesso à Justiça em tempo (decisão tardia só traz indignação); enfim, direitos fundamentais do cidadão.

2 "Bioética e Biodireito: novos desafios do Poder Judiciário". I Ciclo de Estudos de Direito Constitucional e Cidadania do Norte do Paraná. Instituto de Direito Constitucional e Cidadania - IDCC - Londrina-PR 31/10/2005 (site: idcc.sites.uol.com.br. e-mail: constitucional@sercontel.com.br. (0xx43) 33260475). 
O efetivo poder de escolha do cidadão começa pela garantia de seus direitos fundamentais, evoluindo para uma educação cidadã, com vivência de valores cuja perspectiva pode ainda ser ampliada através da arte.

Referindo-se ao Estatuto da Criança e do Adolescente, reconhece José Afonso da Silva $(2002$, p. 23) que a atividade lúdica da criança e do adolescente é imprescindível à sadia formação da personalidade do homem de amanhã:

Diversões, como teatro, dança, música, esportes, segundo as opções de cada um, estimulam o espírito criador e as fantasias criativas da criança e do adolescente, e dão vazão à sua inquietude dinâmica, com o que empregam sua atenção em algo sadio, antes que em situações prejudiciais ao seu desenvolvimento. Não basta, claro está, reconhecer a liberdade de brincar, de praticar esportes e se divertir. É necessário oferecer meios que propiciem à toda criança e aos adolescentes, em geral, o pleno exercício dessa liberdade a fim de que se torne efetivo à cultura, lazer, esportes, diversões, espetáculos previstos no artigo 71.

E a vivência da arte traz perspectivas ao indivíduo no processo de formação cidadã. A vida enxergada em preto e branco não faz inovações. A vida é um dado com cores, profundidades, texturas, cheiros e sabores. O indivíduo que vive a arte enxerga sim: um dado com perspectivas.

Destaca-se o papel da sociedade civil na construção da cidadania, no entendimento de Liszt Vieira (2001, p. 37):

\begin{abstract}
A sociedade civil cria grupos e pressiona em direção a determinadas opções políticas, produzindo, conseqüentemente, estruturas institucionais que favorecem a cidadania. Uma sociedade civil fraca, por outro lado, será normalmente dominada pelas esferas do Estado ou do mercado. Além disso, a sociedade civil consiste primordialmente na esfera pública, onde associações e organizações se engajam em debates, de forma que a maior parte das lutas pela cidadania são realizadas em seu âmbito por meio dos interesses dos grupos sociais, embora cabe a ressalva - a sociedade civil não possa constituir o locus dos direitos de cidadania, por não se tratar da esfera estatal, que assegura proteção oficial mediante sanções legais.
\end{abstract}

O bom desempenho da democracia pressupõe a observância dos direitos básicos. Não basta o direito de voto. É preciso garantir os direitos fundamentais e ainda, uma sensibilidade ao votante, trazida pela educação cidadã através da arte. 


\title{
20 poder do judiciário na prevenção de abusos do poder econômico
}

Não há dúvidas do constante abuso de poder e da corrupção no processo eleitoral, destacado por Acórdão ${ }^{3}$ do Tribunal Regional Eleitoral do Paraná:

\begin{abstract}
A distribuição de cestas básicas pelo candidato a Prefeito em reeleição e pela Secretária da Ação Social e do Trabalho, no ano de eleições municipais, em quantidade cinco vezes maior a que vinha ocorrendo em anos anteriores, ausente qualquer controle de seus beneficiários, caracteriza conduta abusiva, pelo poder econômico, com potencialidade de comprometimento da isonomia entre os candidatos e legitimidade do pleito.
\end{abstract}

Para fundamentar sua decisão, os Juízes integrantes do Tribunal Regional Eleitoral do Paraná, no Acórdão supracitado, transcreveram o parecer da Procuradoria Regional Eleitoral:

O legislador levando em conta o bem jurídico a ser protegido - o interesse púbico de lisura eleitoral - atribuiu ao Juiz Eleitoral, para formação de sua convicção, a responsabilidade de analisar os fatos públicos e notórios, indícios e presunções, circunstâncias ou fatos, ainda que não indicados ou alegados pelas partes, no mesmo plano valorativo das provas produzidas nos autos.

Verifica-se não só uma potencialidade de comprometer a lisura do pleito quando o candidato entrega quantidade absurdamente maior do que costumava entregar como Ação Social quando Prefeito: há total anulação do direito de escolha do cidadão. O Brasil passa fome. Crianças, quando não morrem pela falta de qualquer alimento, crescem desnutridas. $E$ isto não se restringe ao Nordeste. Dar comida a quem tem fome é o grande trunfo dos candidatos sem qualquer comprometimento político. Saciar a fome é garantia de votos por gerações numa família que passa por necessidades vitais.

Infelizmente este fato só é analisado em eleições. O Poder Judiciário, ciente da fome que alastra o Brasil, deve forçar a implementação de políticas públicas pelo Poder Executivo. A fome não pode permanecer, para não ser usada por falsários políticos. 0 jogo de interesses econômicos se engrandece exatamente nesse desequilíbrio dos Poderes. Inconteste a lição de Ingo Wolfgang Sarlet (2001, p. 39) de que:

3 Acórdão 25.990 (de julho de 2002) de Recurso Eleitoral no 1438/02 -Classe 2a, Procedente de Araucária-50ạ Zona Eleitoral. 
Não devem - especialmente o Juiz e os demais operadores do Direito simplesmente capitular diante das 'forças reais de poder' (Lassale) ou em face da alegação de que inviável o reconhecimento de um direito subjetivo a prestações, socorrendo-se dos limites fáticos da reserva do possível e argumentando que inexiste dotação orçamentária, pena de esvaziamento completo da eficácia dos direitos sociais. O que se verifica, em verdade, é que o aumento da opressão sócioeconômica e a elevação dos níveis de desigualdade fática fazem com que o reconhecimento e efetivação dos direitos sociais, ainda que em patamar mínimo, voltado à manutenção de um nível existencial digno, transformem-se em meta indispensável a qualquer ordem estatal que tenha a pretensão de ostentar o título de genuinamente democrática.

A alegação da discricionariedade administrativa no direcionamento do dinheiro do povo não pode ser restrita à reserva do possível. O povo, com fome e mesmo sem qualquer educação cidadã sabe que os Poderes não o favorecem. O desequilíbrio entre os três Poderes é evidente. Urge a ação do Poder Judiciário (Dallari, 1996, p. 36, 88, 161-163):

\begin{abstract}
Mas o juiz não decide nem ordena como indivíduo e sim na condição de agente público, que tem uma parcela de poder discricionário, bem como de responsabilidade e de poder de coação, para a consecução de certos objetivos sociais. [...] É obvio que o Judiciário faz parte da sociedade e não poderá, sozinho, fazer o milagre de eliminar as injustiças institucionais e os vícios de comportamento que impedem o Brasil, assim como outros países, de viver democraticamente e com justiça social. Mas uma boa organização judiciária, tendo juízes verdadeiramente comprometidos com a realização da justiça, desde a primeira instância até os mais altos tribunais, será mais um instrumento valioso para a proteção da legalidade autêntica e promoção da dignidade humana. [...] Ao Judiciário foi atribuído o papel da guarda da Constituição, protetor dos direitos e promotor da paz, ampliando-se suas atribuições e aumentando-se sua responsabilidade à medida que os demais Poderes fracassaram no desempenho de seus encargos. [...] Por esse motivo buscam-se novas soluções dentro dos esquemas tradicionais de organização e foi por esse caminho que se chegou ao Judiciário ativo e militante, com papel político reconhecido, admitindo-se que ele seja o complementador das normas constitucionais, o que, em princípio, cria menos riscos do que a complementação feita pelo Executivo. Evidentemente, embora enfraquecido está ainda presente o pressuposto, muitas vezes desmentido na prática, de neutralidade política dos juízes e tribunais. [...] Agora, mais do que nunca, é indispensável que os juízes participem ativamente das discussões a respeito de seu papel social e procurem, com serenidade e coragem, indicar de que modo poderão ser mais úteis à realização da justiça.
\end{abstract}

Justamente nestes momentos de abuso do poder econômico o Poder Judiciário tem contato direto com a omissão do Poder Executivo. Cada Magistrado tem consciência das falhas da política pública sob sua jurisdição e nesse momento, deve agir. Não há que se esperar o acionamento do Poder Judiciário para efetiva garantia dos direitos fundamentais. Do contrário, ao povo só restaria esperar a ação avassaladora do 4 o Poder: o crime 
organizado no tráfico de drogas; contrabando de armas; crianças e mulheres; lavagem de todo esse dinheiro.

Ressalta Ingo Wolfgang Sarlet (2001, p. 29) o poder do Judiciário, citando Flávia Piovesan e Eros Roberto Grau respectivamente:

\begin{abstract}
Sustentou-se acertadamente que a norma contida no artigo 5o, $\S 10$, da Constituição Federal, impõe aos órgãos estatais a tarefa de maximizar a eficácia dos direitos fundamentais. Além disso, há que dar razão aos que ressaltam o caráter dirigente desta norma, no sentido de que esta, além do objetivo de 'assegurar a força vinculante dos direitos e garantias de cunho fundamental, tem por finalidade tornar tais direitos prerrogativas diretamente aplicáveis pelos Poderes Legislativos, Executivo e Judiciário, [...] investe os poderes públicos na atribuição constitucional de promover as condições para que os direitos e garantias fundamentais sejam reais e efetivos'. Deste sentido, aproxima-se a lição de Eros Roberto Grau, ao sustentar que o Poder Judiciário, em face do dever de respeito e aplicação imediata dos direitos fundamentais ao caso concreto, encontra-se investido do poder-dever de aplicar imediatamente estas normas, assegurandoIhes sua plena eficácia.
\end{abstract}

O direito de escolha do cidadão deve ser garantido, antecedendo qualquer forma de participação na organização da sociedade. O Poder Judiciário tem fundamental papel nessa garantia, quando os Poderes Executivo e Legislativo falham em suas funções. Deve-se equilibrar o que está desequilibrado.

\title{
3 Repressão dos abusos pelo artigo 41-a da Lei no 9.504/97
}

Ressalvando-se os gastos eleitorais considerados no artigo 26 da Lei no 9.504/97, dispõe o artigo 41-A da mesma Lei que constitui a vedada captação irregular de sufrágio:

[...] o candidato doar, oferecer, prometer, ou entregar, ao eleitor, com o fim de obter-Ihe o voto, bem ou vantagem pessoal de qualquer natureza, inclusive emprego ou função pública, desde o registro da candidatura até o dia da eleição, inclusive, sob pena de multa de mil a cinqüenta mil UFIR, e cassação do registro ou do diploma, observado o procedimento previsto no art. 22 da Lei Complementar no 64, de 18 de maio de 1990.

Por iniciativa popular (Lei no 9.840/99) houve a inserção do artigo 41-A na Lei 9.504/97, podendo a investigação judicial eleitoral nesse caso ser instaurada desde o registro da candidatura até a diplomação, obtendo a cassação do registro ou do diploma de candidato que tenha violado o preceito daquele artigo. Pune atos imorais daqueles que 
pretendem ser destinatários da representatividade popular, considerando a individualidade do eleitor no seu direito de livre escolha, com evidente tratamento diferenciado dos casos de abuso de poder que danificam a eleição como um todo e implicam em inelegibilidade. Nos ensinamentos de Emerson Garcia (2004, p. 203-204):

Ainda que a decisão seja proferida posteriormente à proclamação dos eleitos, produzirá ela efeitos imediatos, sendo desnecessário aguardar o seu trânsito em julgado ou mesmo ajuizar qualquer outra ação. (...) Sendo possível a produção de efeitos imediatos, não se verificará, com o tramitar do feito e a inevitável utilização das irresignações recursais, a paulatina deterioração da carga sancionatória. Por essa razão deve o legitimado à propositura da ação ter grande cautela ao invocar a potencialidade do ato para afetar a normalidade do pleito, pois, o fazendo, além de tornar possível a aplicação da sanção de inelegibilidade, trará à baila o anacrônico sistema vigente em relação à investigação judicial eleitoral, que prevê o efeito suspensivo dos recursos, acarretando a quase que total ineficácia da referida sanção, que começa a fluir a contar da eleição e, pior, a transmudação da investigação judicial em mero instrumento para o ajuizamento de outra medida sempre que a decisão for proferida após a proclamação dos eleitos.

Para Joel J. Cândido (2004, p. 459) pelo artigo 41-A da Lei 9.504/97:

[...] a sanção da cassação do registro só é possível se o processo for julgado até a eleição, pois, a partir desta, de registro não se pode mais falar; e, a sanção da cassação do diploma é absolutamente inviável e inaplicável pela via do artigo 41-A, pois a medida se erigiria em inelegibilidade, mesmo que só para uma eleição, restrição aos direitos políticos insuscetível de constar em sede de lei ordinária como o é a Lei no 9.840, de 28.9.1999 (CF, art. 14, § 9ㅇ).

Jurisprudência acertada do Tribunal Superior Eleitoral abala o entendimento do nobre jurista:

Representação. Art. 41-A da Lei no 9.504/97. Captação de sufrágio vedada por lei. Comprovação. Aplicação de multa. Decisão posterior à diplomação. Cassação do diploma. Possibilidade. Ajuizamento de ações próprias. Não-necessidade. A decisão que julgar procedente representação por captação de sufrágio vedada por lei, com base no art. 41-A da Lei no 9.504/97, deve ter cumprimento imediato, cassando o registro ou o diploma, se já expedido, sem que haja necessidade de interposição de recurso contra expedição de diploma ou de ação de impugnação de mandato eletivo (REsp. no 19.739, rel. Min. Fernando Neves, j. em 13/8/2002, DJ de 4/10/2002, p. 233).

Citando Tito Costa, França e Silva (2003, p. 52) concorda que: 
Separadamente, ou dentro do Código Eleitoral, deverá estabelecer rito especial, mais célere e mais consentâneo com a natureza da ação e suas conseqüências. Porque, tal pode ser a demora, que o impugnado acabará por cumprir seu mandato, sem que ocorra o desfecho da demanda. Isso poderá tornar letra morta o texto constitucional que, para não ser cumprido, melhor seria não ter sido escrito.

Além da decretação da perda do registro, do diploma e da multa estabelecidas como sanções do art. 41-A, urgente a necessidade de maior punição, acrescentando via Lei Complementar, também, a inelegibilidade pelo prazo mínimo de 6 (seis) anos, contados do trânsito em julgado da sentença condenatória (CASTRO, 2004.p. 42).

A maior preocupação é com o direito de escolha do cidadão, mas também abre um precedente para o indigno jogo de interesses econômicos. Os eleitores que recebem ou solicitam vantagens, muitas vezes comparecem ao processo na condição de testemunhas, provavelmente arregimentadas pelos adversários políticos e contra eles não prossegue a investigação. Não podem produzir prova contra si que possa ser utilizada em posterior ação penal. O Poder Judiciário deve aferir as provas com extrema cautela e sensibilidade, pois o dispositivo em análise também vai contra o político inocente, vítima do poder econômico.

Entende o TRE-PR que para comprovar o abuso de poder econômico é necessário prova inequívoca, não bastando meras alegações de testemunhas que têm interesse no desfecho quando é visível que houve o preparo de situação para dar a característica de ilícito ${ }^{4}$. Infere-se a preocupação com o jogo de interesses. Afasta-se a aferição da potencialidade de desequilíbrio da disputa eleitoral porque o interesse tutelado pelo artigo 41- A da Lei no 9.504/97 é a livre vontade do eleitor e não a normalidade e equilíbrio do pleito ${ }^{5}$.

Percebe-se que o cuidado do Magistrado ao analisar o caso concreto tem uma escala de prioridades: analisar sempre o jogo de interesses econômicos que envolve a eleição, mas tendo como prioridade tutelar o direito de escolha do cidadão. E neste ponto o Poder Judiciário deve aprofundar sua atuação, para análise e justiça da implementação de políticas públicas que garantam o direito de escolha num Estado que se diz democrático. $\mathrm{O}$ voto deve ser livre, legítimo, conferido ao candidato de maneira proba, e principalmente, consciente, ou este voto é viciado, conforme Cotosky (2004, p.62) que afirma que o valor irrisório aos olhos de um aplicador do Direito pode ser algo de grande valia para quem vive

\footnotetext{
4 RE 4111. 30145. Acórdão em 15/09/2005.

5 RE 3933. 29858. Acórdão em 30/05/2005.
} 
na linha da pobreza, ou abaixo dela. A grande valia de um operador do direito é ir além dos olhos, trilhar pedra por pedra um ideal: direitos fundamentais garantidos para idealizar uma democracia.

Enuncia França e Silva (2003, p. 47) :

O Tribunal Superior Eleitoral adotou posição restritiva, segundo a qual os eleitores não têm legitimidade ad causam. (Rec. o 11.835 - Classe 4a - PR, 9.6.1994) Com opiniões contrárias ao TSE, no sentido de reconhecer legitimidade ativa aos eleitores, encontramos Tito Costa e Adriano Soares da Costa.

Para Marcos Antônio Striquer Soares (2001, p. 35 e 37), apesar da participação do cidadão no processo eleitoral "ser fundamental para o bom resultado das eleições", fica restrita à notícia fundamentada da inelegibilidade de alguém que esteja solicitando o registro de candidatura:

Considerando a possibilidade de dois procedimentos distintos para o registro de candidatura, um administrativo e outro jurisdicional, já podemos verificar que não é permitida a participação do cidadão comum no procedimento contencioso, na ação judicial. Ele não pode oferecer impugnação (nos termos do art. 3o da lei complementar 64/90). Qualquer participação dele em um procedimento de registro, não lhe dá direito a exame de provas, a intimação para acompanhamento de atos judiciais, a alegações finais ou a recursos. Isto porque ele não será parte numa relação jurídica processual.

Porém ressalta Tito Costa (2000, p. 182) que:

O TSE entende que os apenas eleitores não têm legitimidade ad causam para propor ação (Rec. 11.835, classe 4a - PR, em 9.6.94). Esse entendimento, a nosso ver, não encontra respaldo na Constituição. A restrição contida no art. 22 da LC $64 / 90$ não pode sobrepor-se ao estatuído no art. 14 , $\S \S 10$ e 11 da Carta de 88, que é amplo e não discrimina quem pode agir como autor nessa ação.

Obviamente, para um ideal de democracia participativa, o cidadão deve participar da organização da sociedade. Sabendo-se do verdadeiro jogo de interesses que perfaz cada eleição, a realização da justiça na eleição ocorre quando da análise profunda do direito de escolha do eleitor. O abuso do poder econômico deve ser punido, mas pode haver envolvimento de um eleitor que, mesmo no contexto, não tem seu direito de escolha abalado, porque Ihe foi garantida vida digna durante a formação política, embora optasse 
em vender sordidamente seu voto. Seu direito de escolha não foi abalado por falta de políticas públicas. Há consciência no que faz.

Jamais esquecendo que o jogo de interesses envolve mentira. Testemunhas são compradas. São estas as circunstâncias que devem influir na decisão do feito, que julgado procedente acarretará aplicação de multa e cassação do registro ou diploma do candidato diretamente beneficiado pela interferência do poder econômico e pelo desvio ou abuso do poder de autoridade, com remessa dos autos ao Ministério Público Eleitoral para instauração de processo disciplinar e processo-crime. As conseqüências são graves para um candidato inocente, portanto a sensibilidade da Justiça Eleitoral é essencial.

\section{Considerações finais}

Necessário se faz a busca incessante pela efetivação do direito de escolha, em especial quanto à delicadeza existente sobre a ação de investigação judicial eleitoral, diante do jogo de interesses econômicos que envolvem as questões eleitorais, pela importância do tema para a democracia.

Num perfil entre os procedimentos eleitorais tem-se como cerne o direito de escolha do cidadão, compromisso pessoal de todo jurista no avanço social.

Desnecessária a ação de impugnação de mandato eletivo nas hipóteses do artigo 41-A da Lei no 9.405/97, bastando a investigação judicial eleitoral para reprimir a afronta ao direito de escolha do cidadão, garantia constitucional no conjunto dos direitos fundamentais.

Salienta-se a intenção de viabilizar maior efetividade das garantias fundamentais do cidadão, firmando-se verdadeira contribuição social desta pesquisa.

Porém todo cuidado é essencial na investigação judicial eleitoral sobre hipótese de abuso do poder econômico diante dos interesses envolvidos, podendo apagar qualquer feixe de luz do ideal de democracia.

Castro (2004, p. 45), resumindo um conto que retrata o que se espera da Justiça, tirado do artigo "da Justiça à Democracia, passando pelos sinos", de José Saramago, ressalta que no século XVI a morte de um aldeão era anunciada com o tocar dos sinos. Certo dia, sem morte alguma e ainda na ausência do sineiro, os sinos tocaram. Surgiu então um camponês confessando: 'Toquei a finados pela Justiça, porque a Justiça está morta'. Protesto contra o 
senhor do lugar, algum conde ou marquês sem escrúpulo que andava a trocar os marcos das divisas de suas propriedades confinantes, assenhorando-se de suas terras mais e mais reduzida a cada avançada, que levara o camponês a protestar, reclamar, a implorar compaixão, até que socorreu-se à Justiça. Tudo sem resultado. A espoliação continuava. Então, desesperado decidiu anunciar urbi et orbi ${ }^{6}$ a morte da Justiça. Talvez pensasse que seu gesto de exaltada indignação lograria comover a todos e por a tocar todos os sinos do universo, sem diferença de raças, credos e costumes que todos eles, sem exceção, os acompanhariam no dobre a finados pela morte da Justiça, e não se calariam até que ela fosse ressuscitada. O Mestre Português, não informa o fim da estória, supondo ter sido esta a única vez que, em qualquer parte do mundo, um sino, uma campânula de bronze inerte, depois de tanto haver dobrado pela morte de seres humanos, chorou a morte da Justiça.

O Magistrado, na sua essência de anunciar a Justiça, não pode deixar ser anunciada pelo dobre do sino a morte da Justiça por omissão. Não só no momento do pleito o Magistrado deve estar atento à precária situação vivida pelos cidadãos. São momentos como a compra de voto que evidenciam o caos político que enfrentamos. A democracia deve ser vivida em sua plenitude, embora comece por pequenas ações da sociedade civil organizada, jamais esquecendo o papel garantidor do Estado que se diz democrático. Se os três Poderes não agem, um deles deve equilibrar o Estado: aí está o papel do Poder Judiciário na segurança de pequenos raios deste imenso sol idealizado na democracia. Momentos que o cidadão merece no seu direito de escolha, para que o Estado democrático o seja realmente no futuro.

\section{Referências}

BUENO, Pimenta. Direito Público brasileiro e análise da constituição do império. Rio de Janeiro: Nova Edição, 1958.

CÂNDIDO, Joel J. Direito Eleitoral Brasileiro. 11. ed. Edipro: Bauru, 2004.

CASTRO, Honildo Amaral de Mello. Transparência e Confiabilidade do Processo Eleitoral. Paraná Eleitoral, Curitiba, p. 39-46, jul./dez. 2004.

6 Urbi et orbi. Expressão latina de "cidade e mundo". Assevera o autor que "uma aldeia tem exato tamanho do mundo para quem sempre nela viveu". 
COSTA, Tito. Recursos em Matéria Eleitoral. 7. ed. São Paulo: Revista dos Tribunais, 2000.

COTOSKY, Alessandra Anginski. Corrupção Eleitoral Passiva e o Princípio da Insignificância. Paraná Eleitoral, Curitiba, p. 59-68, maio/jun. 2004.

DALLARI, Dalmo de Abreu. O poder dos juízes. São Paulo: Saraiva, 1996.

FRANÇA e SILVA, Ana Flora. A ação de Impugnação de Mandato. Paraná Eleitoral, Curitiba, p. 41-57, out./dez. 2003.

GARCIA, Emerson. Abuso de Poder nas Eleições - Meios de Coibição. 2. ed. Rio de Janeiro: Lumen Juris, 2004.

MORAES, Alexandre de. Direito Constitucional. 17. ed. São Paulo: Atlas, 2005.

OLIVEIRA, Francisco de. Democratização e Republicanização do Estado. Teoria \& Debate, São Paulo, v. 16, n. 54, p. 52-57, jun./ago. 2003.

SARLET, Ingo Wolfgang. Os Direitos Fundamentais Sociais na Constituição de 1988. Revista Diálogo Jurídico, Salvador, v. 1, n. 1, p. 1-45, abr. 2001.

SILVA, José Afonso da. Direitos Humanos da Criança. Igualdade, Curitiba, p. 8-26, out./dez. 2002.

SOARES, Marcos Antônio Striquer. A Ação de Impugnação de Registro de Candidatura e notícia de inelegibilidade trazida pelo cidadão comum. Paraná Eleitoral, Curitiba, p. 31-41, jul./set. 2001.

VIEIRA, Liszt. Os Argonautas da cidadania. A sociedade civil na globalização. Rio de Janeiro: Record, 2001. 
